\title{
Corrigendum
}

\section{Corrigendum to "Claudin-1 Is a Valuable Prognostic Biomarker in Colorectal Cancer: A Meta-Analysis"}

\author{
Didi Zuo ${ }^{1}{ }^{1}{ }^{1}$ Jiantao Zhang, ${ }^{2}$ Tao Liu, ${ }^{2}$ and Chao Li $\mathbb{D}^{2}$ \\ ${ }^{1}$ Department of Endocrinology and Metabolism, The First Hospital of Jilin University, Changchun, China \\ ${ }^{2}$ Department of Colorectal and Anal Surgery, The First Hospital of Jilin University, Changchun, China \\ Correspondence should be addressed to Chao Li; lichao37521@163.com
}

Received 5 October 2020; Accepted 5 October 2020; Published 16 October 2020

Copyright (C) 2020 Didi Zuo et al. This is an open access article distributed under the Creative Commons Attribution License, which permits unrestricted use, distribution, and reproduction in any medium, provided the original work is properly cited.

In the article titled "Claudin-1 Is a Valuable Prognostic Biomarker in Colorectal Cancer: A Meta-Analysis" [1], Dr. Guang Ning is to be removed from the author list. All authors have agreed with the updated author list, which is shown above.

\section{References}

[1] D. Zuo, J. Zhang, T. Liu, C. Li, and G. Ning, "Claudin-1 is a valuable prognostic biomarker in colorectal cancer: a metaanalysis," Gastroenterology Research and Practice, vol. 2020, Article ID 4258035, 10 pages, 2020. 